\title{
Medical Image of the Week: Sarcoidosis
}

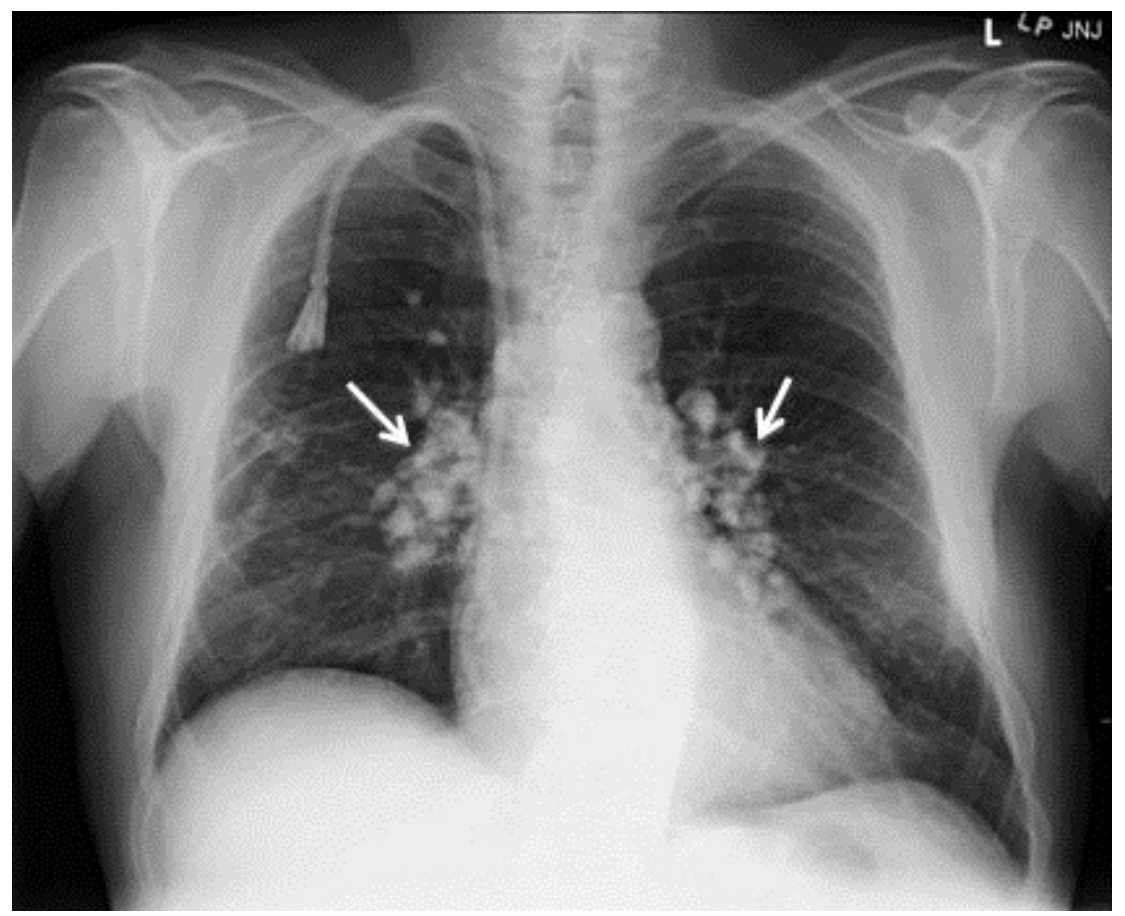

Figure 1. The AP supine chest radiograph depicts bilateral hilar calcified lymphadenopathy with characteristic popcorn appearance of the lymph nodes (white arrows). Incidentally noted are a tunneled dialysis catheter terminating in the right atrium and median sternotomy wires from a previous coronary artery bypass graft surgery.

We present a 58-year-old African American man with a complicated medical history including long-standing sarcoidosis that has caused him chronic, unrelenting pain for two decades. He initially underwent placement of an intrathecal morphine pump, but recently began complaining of increasing pain. Consequently, he was seen at our hospital for interrogation of his pain pump by the interventional radiologist, and was incidentally noted to have bilateral calcified hilar lymphadenopathy on fluoroscopic imaging. A dedicated chest $\mathrm{x}$-ray confirmed the abnormality, which was consistent with his known diagnosis of sarcoidosis.

Sarcoidosis is a complex disease process characterized by noncaseous granulomas that can affect various organ systems, with pulmonary involvement in up to $90 \%$ of cases (1). Though sarcoidosis is a diagnosis of exclusion, clinicians should recognize that bilateral hilar lymphadenopathy is highly concerning for the underlying noncaseating granulomatous disease (2). The most common pattern of lymphadenopathy is well-defined, bilateral, symmetric hilar and right paratracheal lymph node enlargement. Bilateral hilar lymph node enlargement, alone or in combination with mediastinal lymph node enlargement, occurs in an estimated $95 \%$ of patients affected 
with sarcoidosis (1). Although bilateral hilar adenopathy may be a feature of other disease processes including infections (especially fungal or mycobacterium) and malignancy (metastases or lymphoma), sarcoidosis is the most common cause of bilateral hilar lymphadenopathy in the absence of specific clinical features of these processes. The enlarged lymph nodes eventually calcify, and the chronicity of the disease process directly correlates to hilar lymphadenopathy calcification, occurring in up to $20 \%$ of patients after 10 years (3). Of note are the popcorn like calcifications within perihilar lymph nodes silhouetting the normal vascular anatomy (Figure 1).

Amrit Hansra, MD and Unni Udayasankar, MD

Department of Medical Imaging

University of Arizona

Tucson, AZ

\section{References}

1. Criado E, Sánchez M, Ramírez J, Arguis P, de Caralt TM, Perea RJ, Xaubet A. Pulmonary sarcoidosis: typical and atypical manifestations at high-resolution CT with pathologic correlation. Radiographics. 2010;30(6):1567-86. [CrossRef] [PubMed]

2. Baughman RP, Culver DA, Judson MA. A concise review of pulmonary sarcoidosis. Am J Respir Crit Care Med. 2011;183(5):573-81. [CrossRef] [PubMed]

3. Miller BH, Rosado-de-Christenson ML, McAdams HP, Fishback NF. Thoracic sarcoidosis: radiologic-pathologic correlation. Radiographics. 1995;15(2):421-37. [CrossRef] [PubMed] 